
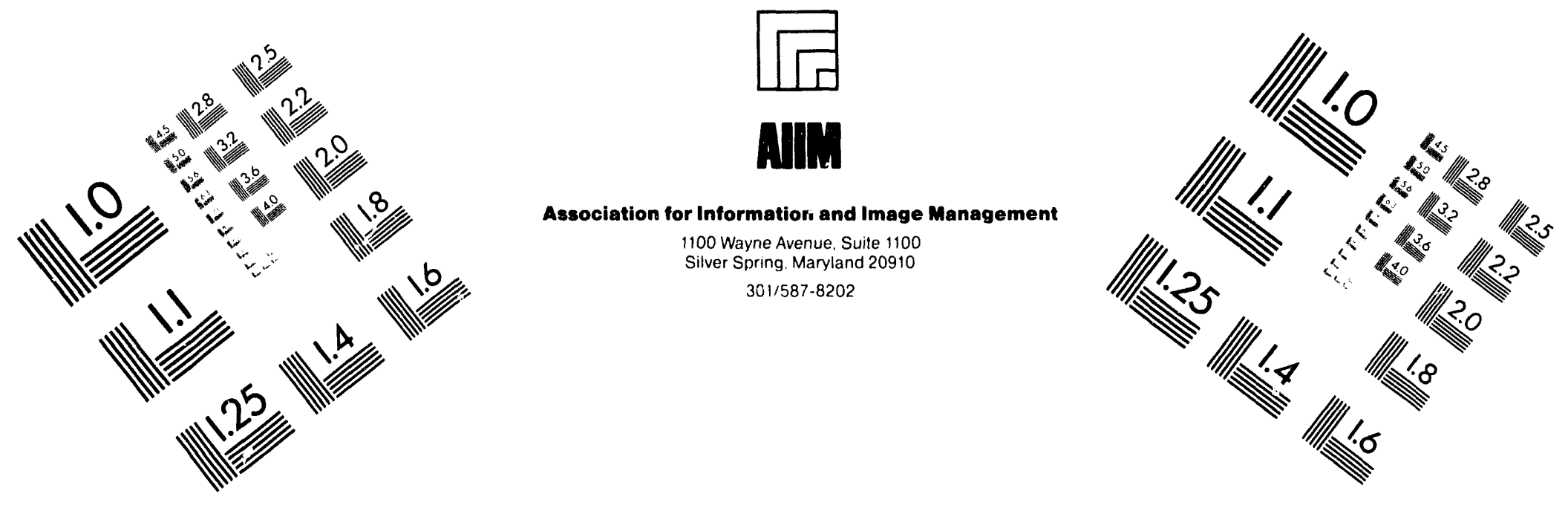

\title{
Centimeter
}

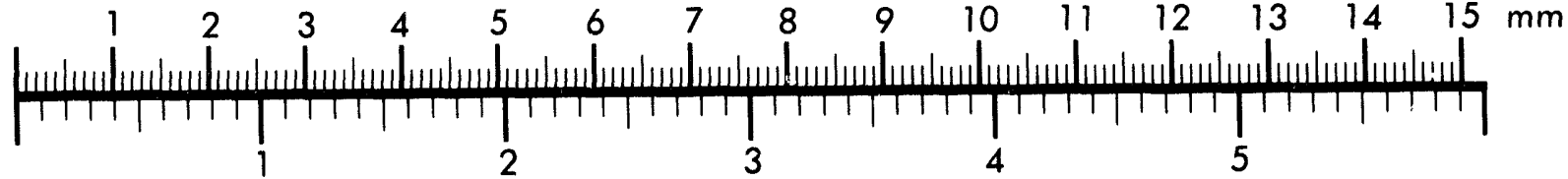

Inches
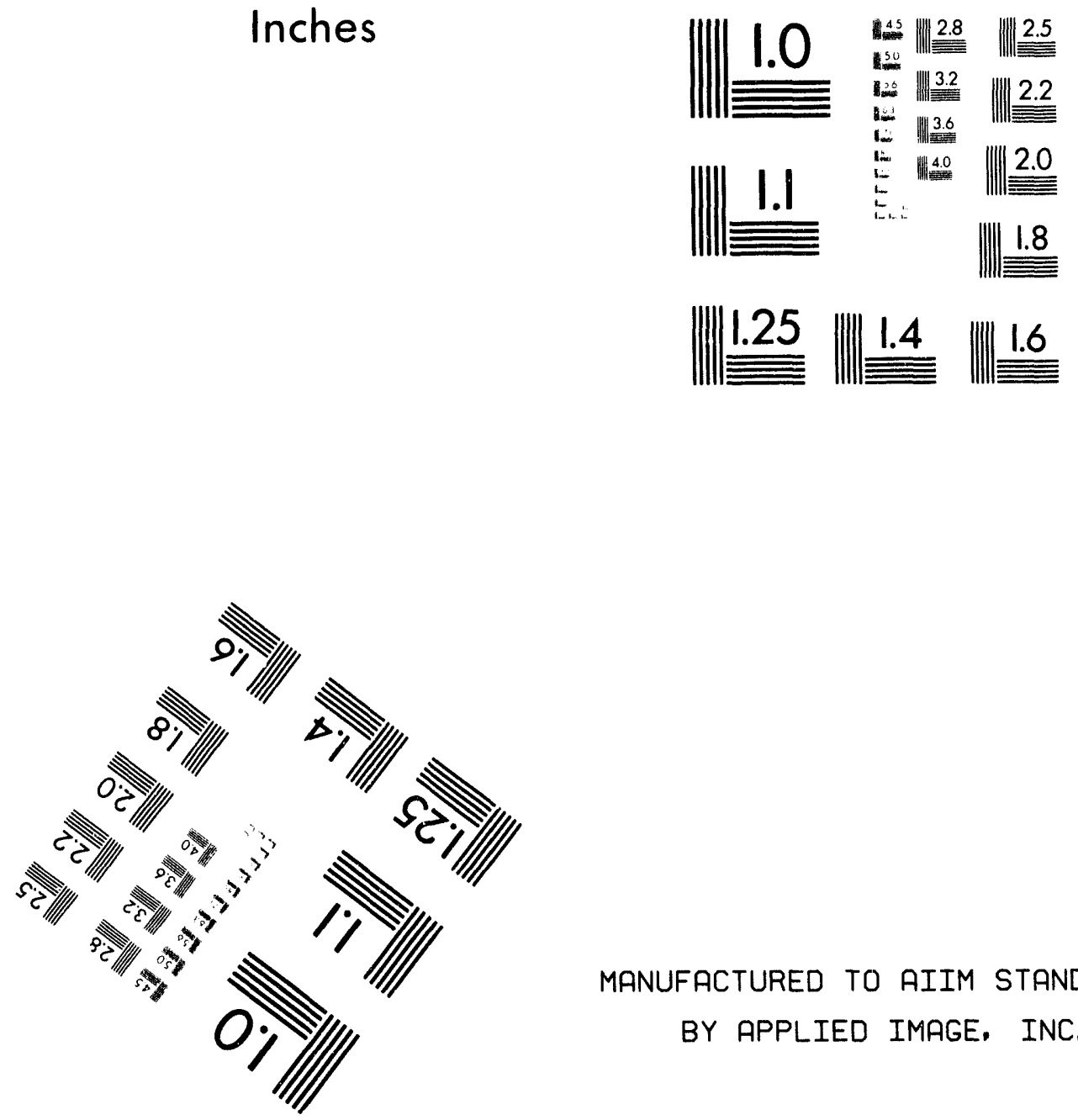

MANUFACTURED TO AIIM STANDARDS

BY APPLIED IMAGE, INC.

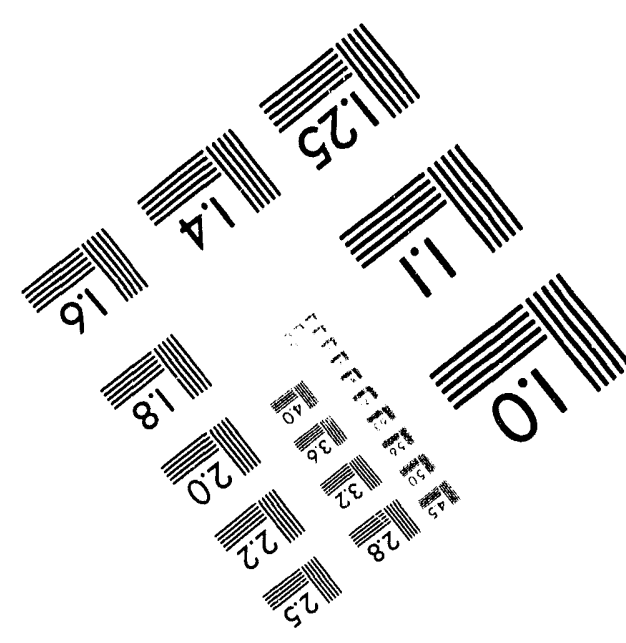



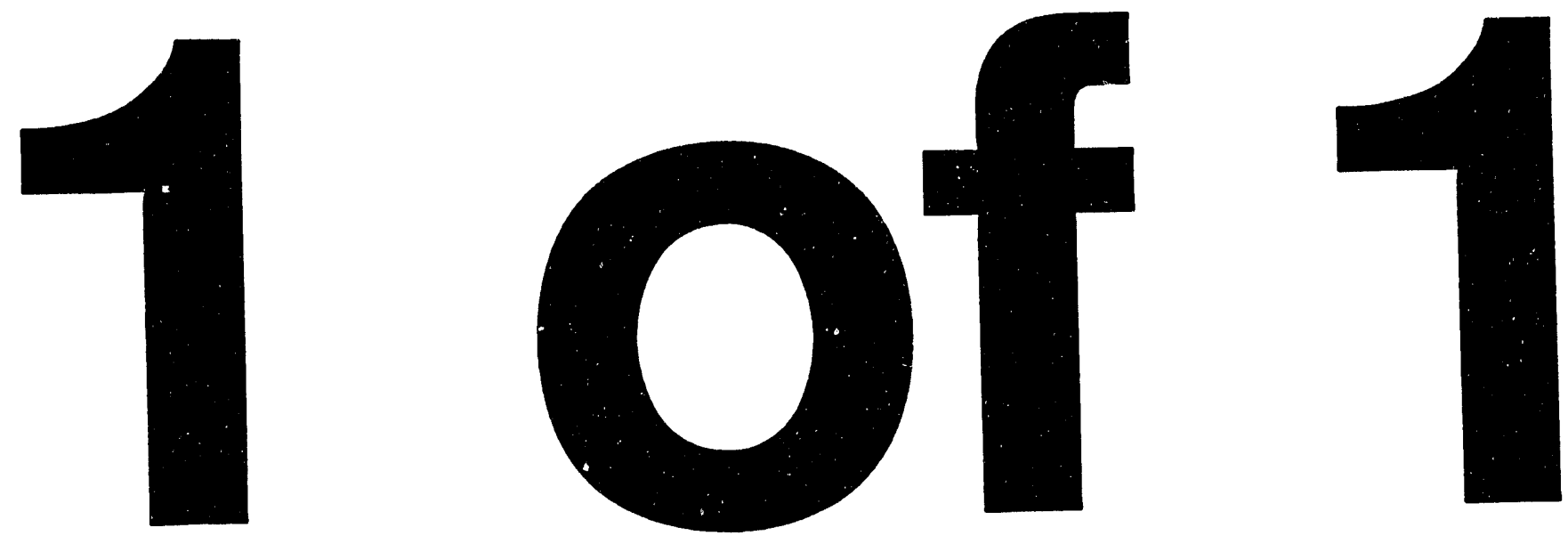


\section{Robust Lateral Control of Highway Vehicles ${ }^{1}$}

\author{
Raymond H. Byrne \\ Sandia National Labs \\ Dept. 9616, MS 1125 \\ Albuquerque, NM 87185-1125 \\ email ray@orion.eece.unm.edu
}

\author{
Chaouki Abdallah \\ Universit, of New Mexico \\ EECE Dept. \\ Albuquerque, NM 87131 \\ email chaouki@eece.unm.edu
}

\begin{abstract}
Vehicle lateral dynamics are affected by vehicle mass, longitudinal velocity, vehicle inertia, and the cornering stiffness of the tires. All of these parameters are subject to variation, even over the course of a single trip. Therefore, a practical lateral control system must guarantee stability, and hopefully ride comfort, over a wide range of parameter changes. This paper describes a robust controller which theoretically guarantees stability over a wide range of parameter changes. The robust controller is designed using a frequency domain transfer function approach. An uncertainty band in the frequency domain is determined using simulations over the range of expected parameter variations. Based on this bound, a robust controller is designed by solving the Nevanlinna-Pick interpolation problem. The performance of the robust controller is then evaluated over the range of parameter variations through simulations.
\end{abstract}

\subsection{INTRODUCTION}

One of the fundamental goals of the Intelligent Vehicle-Highway Systems (IVHS) community is to develop automated highways where vehicles are capable of automatically driving down the road, either individually or in platoons of multiple vehicles. In order to implement such a system, a controller that can keep the vehicle centered in the lane is required. There are many factors which make automatic lateral control of vehicles difficult. These include changing vehicle parameters (tire pressure, tire wear, etc.), changing road conditions (rain, ice, bumps, crowns, etc.), as well as disturbances caused by wind and other factors. Another important consideration is driver comfort while performing lane changes and reacting to disturbances.
Initial research efforts on automated highway systems (AHS) were conducted by the Radio Corporation of America in cooperation with General Motors in the late 1950's [1],[2]. A significant amount of research, including the development of prototype experimental equipment, was conducted at Ohio State University between 1964-1980 |3|-|12|. This included research on both lateral and longitudinal control of highway vehicles. The largest current advanced vehicle control system (AVCS) research effort is being conducted as part of the Program on Advanced Vehicle Technology for the Highway (PATH, more recently Partners for Advanced Transit and Highways (16]) in California [13]-\{16].

The PATH program has been investigating a frequency shaped linear quadratic (FSLQ) optimal control approach for the lateral controller, with feedforward preview control to reduce feedback gains [15],[16]. Although the FSLQ approach incorporates ride qualities into the performance index, other work which attempts to design a lateral controller taking into account ride comfort is described in [20]. Recent work on robust control applied to car steering is described in $|17|-\mid 19]$. While many of the previously mentioned efforts rely on buried magnets, electrified wires, or a microwave radar to determine the vehicle's lateral position, another promising approach involves using vision. Efforts at Carnegie Mellon University (CMU), at the National Institute of Standards and Technology (NIST), and in Germany have yielded promising experimental result; using neural networks and classical vision algorithms [21-23].

This paper describes a robust lateral controller which theoretically guarantees stability over a wide range of parameter changes. The controller is designed with the plant uncertainty modeled as unstructured aduitive perturbations in the frequency domain. This approach, first described in [24], is reviewed in Section 2.0. The modeling of the vehicle's lateral dynamics is discussed in Section 3.0. The controller design and simulation

\footnotetext{
${ }^{1}$ This work was supported by the United States Department of Energy under Contract DE-AC04-94AL85000 and by the Sandia National Laboratories Doctoral Study Program.
} 


\section{DISCLAIMER}

This report was prepared as an account of work sponsored by an agency of the United States Government. Neither the United States Government nor any agency thereof, nor any of their employees, makes any warranty, express or implied, or assumes any legal liability or responsibility for the accuracy, completeness, or usefulness of any information, apparatus, product, or process disclosed, or represents that its use would not infringe privately owned rights. Reference herein to any specific commercial product, process, or service by trade name, trademark, manufacturer, or otherwise does rot necessarily constitute or imply its endorsement, recommendation, or favoring by the United States Government or any agency thereof. The views and opinions of authors expressed herein do not necessarily state or reflect those of the United States Government or any agency thereof. 
results are presented in Sections 4.0 and 5.0. A summary and discussion of planned future research is outlined in Section 6.().

\subsection{ROBUST STABILITY CONDITION FOR UNSTRUCTURED ADDITIVE PERTURBATIONS}

Unstructured additive perturbations in the frequency domain can be described by $(2.1)$, where the nominal plant transfer function is $G_{0}(s)$, and the uncertainty in the transfer function is $\delta G(s)$.

$$
G(s)=G_{0}(s)+\delta G(s)
$$

Using this model for the parameter uncertainty, the following class of systems can be defined.

Definition 2.1 (24): A transfer function $p(s)$ is said to be in the class $C\left(p_{0}(s), r(s)\right)$ if

1) $p(s)$ has the same number of unstable poles as that of $p_{0}(s)$,

2) $\left|p(j w)-p_{0}(j w)\right| \leq|r(j w)|$,

$$
|r(j w)|>0, \quad \forall w \in R
$$

3) $r(s)$ is a stable minimum phase transfer function

From [24], a controller $c(s)$ is a robust stabilizer for $C\left(p_{0}(s), r(s)\right)$ if and only if the closed-loop system is stable for the nominal plant, and

$$
\left\|\left(1+p_{0}(s) c(s)\right)^{-1} c(s) r(s)\right\|_{\infty}<1
$$

where

$$
\|F(s)\|_{\infty}=\sup _{w}|F(j w)| \forall w \in R, F(s) \in H^{\infty}
$$

If the $q$ parameterization, originally described in $|25|$, is introduced where

$$
q(s)=\frac{c(s)}{1+p_{0}(s) q(s)}
$$

The robust stability condition can be written as

$$
\|q(s) r(s)\|_{\infty}<1
$$

For the closed loop system to be internally stable, the following three conditions are placed on $q(s)|26|$,
1) $q(s) \in H^{\infty}$

2) $q(s)$ must have zeros at the poles of $p(s)$ in the right half-plane (RHP).

3) $p(s) q(s)$ must interpolate to 1 at the poles of $p(s)$ in the RHP.

Introduce the function

$$
u(s)=q(s) r(s)
$$

and the robust stability condition can be written as

$$
\|u(s)\|_{\infty}<1
$$

The robust stability problem for additive unstructured perturbations reduces to an equivalent interpolation problem of finding a strictly bounded real (SBR) function $u(s)$ which interpolates at the unstable poles of the nominal plant in the RHP. This interpolation problem is often referred to as the Nevanlinna-Pick interpolation problem.

\subsection{MODEL OF LATERAL DYNAMICS}

A two-degree of freedom bicycle model, described by (3.1) and (3.2), is used to model the lateral dynamics of the vehicle [27].

$$
\begin{aligned}
m \dot{V}_{y} & +\left[m V_{x}+\frac{2 l_{1} C_{u f}-2 l_{2} C_{u x}}{V_{1}} \Omega_{z}\right. \\
& +\left[\frac{2 C_{u f}+2 C_{\alpha x}}{V_{x}} V_{y}=2 C_{u f f} \delta_{f}(\mathrm{t})\right.
\end{aligned}
$$

$$
\begin{aligned}
I_{z} \dot{\Omega}_{z} & +\left[\frac{2 l_{1}^{2} C_{u x j}+2 l_{2}^{2} C_{u x}}{V_{1}}\right] \Omega_{z} \\
& +\left[\frac{2 l_{1} C_{u f}-2 l_{2} C_{u x}}{V_{x}}\right] V_{y}=2 l_{1} C_{\alpha x f} \delta_{f}(t)
\end{aligned}
$$

A description of the coefficients in (3.1) and (3.2) appears in Table 3.1. The estimated nominal values for a GMC Jimmy (Blazer), the planned test vehicle. are outlined in Table 3.2. It is assumed that the parameters will vary over time, and the expected range of variations is also summarized in Table 3.2. For the simulation results in this paper, the velocity and cornering stiffness were varied while the other parameters were held constant. The velocity was varied from $20 \mathrm{~m} / \mathrm{s}(45 \mathrm{mph})$ to $40 \mathrm{~m} / \mathrm{s}(91 \mathrm{mph})$, with 
$30 \mathrm{~m} / \mathrm{s}(68 \mathrm{mph})$ being the nominal velocity. The comering stiffness was varied from 85 to 115 percent of the nominal value.

\begin{tabular}{|l|l|}
\hline Parameter & Description \\
\hline$m$ & Vehicle mass $(\mathrm{kg})$ \\
\hline$V_{x}$ & $\begin{array}{l}\text { Longitudinal velocity (vehicle } \\
\text { coordinates) }(\mathrm{m} / \mathrm{s})\end{array}$ \\
\hline$V_{y}$ & $\begin{array}{l}\text { Lateral velocity }(\text { vehicle } \\
\text { coordinates) }(\mathrm{m} / \mathrm{s})\end{array}$ \\
\hline$l_{1}, l_{2}$ & $\begin{array}{l}\text { Distance from front and rear axles } \\
\text { to c.g. }(\mathrm{m})\end{array}$ \\
\hline$\Omega_{z}$ & Yaw rate about the c.g. $(\mathrm{rad} / \mathrm{s})$ \\
\hline$\delta_{f}$ & Front steering angle $(\mathrm{rad})$ \\
\hline$C_{r}, C_{f}$ & $\begin{array}{l}\text { Front and rear tire cornering } \\
\text { stiffness }(\mathrm{kn} / \mathrm{rad})\end{array}$ \\
\hline$I_{z}$ & Inertia about $\mathrm{z}$-axis $\left(\mathrm{kg} \bullet \mathrm{m}^{2}\right)$ \\
\hline
\end{tabular}

Table 3.1, Summary of Coefficients in Bicycle Model

\begin{tabular}{|l|l|l|}
\hline Parameter & Nominal Value & Range \\
\hline$V_{s}$ & 30 & $0.667-1.33$ \\
\hline$C_{r}, C_{f}$ & 42000 & 0.85 to 1.15 \\
\hline$m$ & 1590 & constant \\
\hline$l_{1}, l_{2}$ & $1.17,1.42$ & constant \\
\hline$I_{v}$ & 3200 & constant \\
\hline
\end{tabular}

Table 3.2, Summary of Expected Parameter Changes

The transfer function from steering angle to lateral path error (at the c.g.) is of the form of (3.3) below.

$$
\frac{E_{f}(s)}{\delta_{f}(s)}=\frac{a_{0} s^{2}+a_{1} s+a_{2}}{s^{2}\left(s^{2}+b_{1} s+b_{2}\right)}
$$

A program was written to determine the bound on the frequency domain uncertainty of the nominal plant as the velocity and cornering stiffness vary over the ranges in Table 3.2. The program finds the magnitude of

$$
|r(j w)|=\left|p_{0}(j w)-p(j w)\right|
$$

where $p_{0}(s)$ is the transfer function of the nominal plant and $p(s)$ is the transfer function of the actual plant as the parameters are varied. The results of the computer simulation are shown in Figure 3.1. The results are plotted as the ratio of $\left|r(s) / p_{0}(s)\right|$. This format of data presentation was chosen because it facilitates the choice of $r(s)$ as a function of $p_{0}(s)$.
This simplifies the calculations required to arrive at the robust controller designed in the next section.

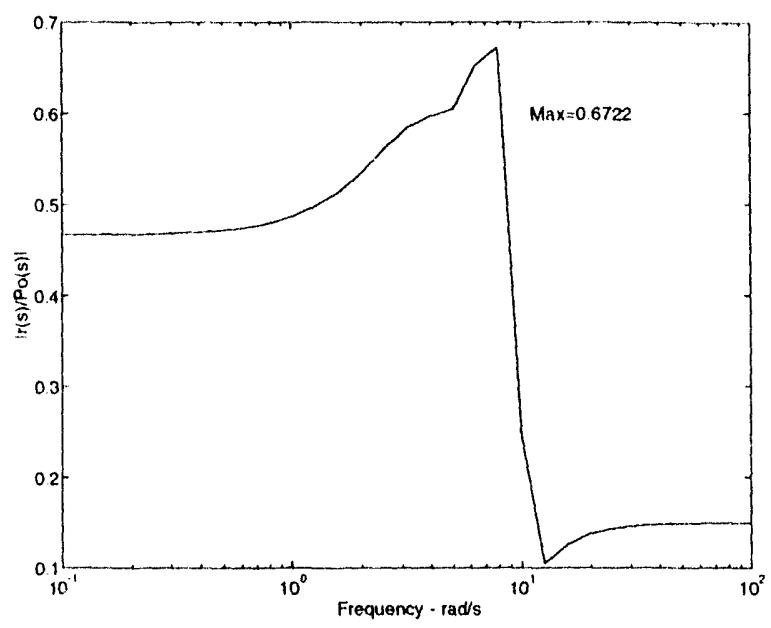

Figure 3.1, Simulation of Plant Uncertainty

\subsection{CONTROLLER DESIGN}

Using the data in Figure 3.1, a conservative bound on the plant uncertainty can be expressed as

$$
r(s)=0.67 p_{0}(s)
$$

Using this bound, a robustly stabilizing controller can be designed if there exists an SBR solution to (2.8). A slight modification must also be made to the approach described in Section 2.0 because the plant has a double pole at the origin. Define

$$
p_{0}(s)=\frac{\tilde{p}(s)}{s^{2}}
$$

where $\tilde{p}(s)$ is a stable transfer function. Similarly, define

$$
r(s)=\frac{r_{m}^{\prime}(s)}{s^{2}}
$$

where $r_{m}^{\prime}(s)$ is a stable minimum phase transfer function. Also define

$$
q(s)=s^{2} \widetilde{q}(s)
$$

where $\tilde{q}(s) \in H^{\infty}$. From (4.3) and (4.4)

$$
q(s) r(s)=\widetilde{q}(s) r_{m}^{\prime}(s)=u(s)
$$


Also.

$$
p_{0}(s) q(s)=\tilde{p}(s) \tilde{q}(s)
$$

Because the plant has two poles at the origin, there are two interpolation conditions that can be written as

$$
u\left(\alpha_{i}\right)=\frac{r_{m}^{\prime}\left(\alpha_{i}\right)}{\tilde{p}\left(\alpha_{i}\right)}=\frac{0.67 \tilde{p}\left(\alpha_{i}\right)}{\tilde{p}\left(\alpha_{i}\right)}=0.67, \alpha_{i}=0
$$

In addition, there are two interpolation points at infinity because $r(s)$ has a relative degree of 2 . An SBR $u(s)$ which meets these interpolation conditions is shown below.

$$
u(s)=\frac{8.04\left(s+\frac{2}{3}\right)}{(s+2)(s+2)(s+2)}
$$

The Bode plot of $u(s)$ is shown in Figure 4.1. Because $u(s)$ is an SBR function, the magnitude is strictly less than 1 .

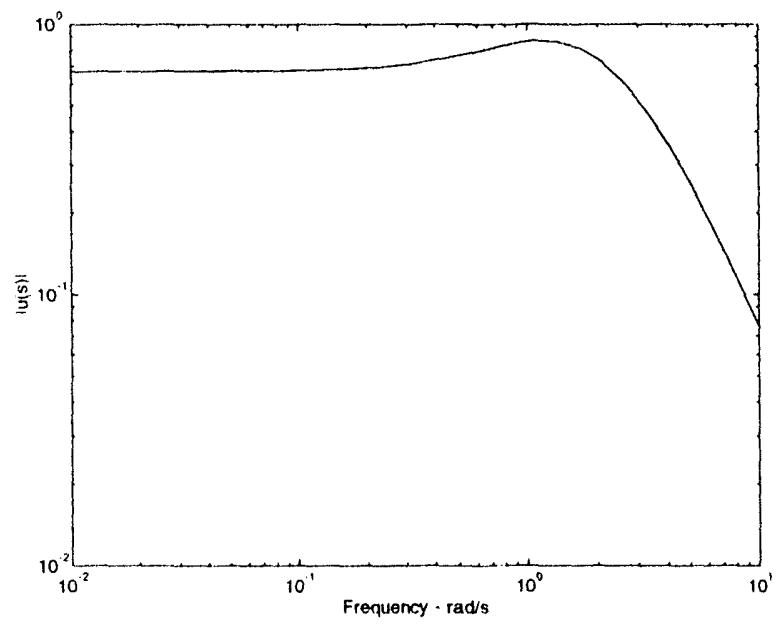

Figure 4.1, Bode Plot of $u(s)$

Using (4.5)

$$
q(s)=\frac{u(s)}{r(s)}=\frac{u(s)}{0.67 p_{0}(s)}
$$

The robustly stabilizing controller is given by

$$
c(s)=\frac{q(s)}{1-p_{0}(s) q(s)}
$$

The nominal plant transfer function for the parameters in Table 3.2 is

$$
p_{0}(s)=\frac{52.8302\left(s^{2}+3.2181 s+67.9875\right)}{s^{2}\left(s^{2}+6.4842 s+16.8989\right)}
$$

The controller can then be expressed as

$$
c(s)=\frac{12\left(s+\frac{2}{3}\right)\left(s^{2}+6.4842 s+16.8989\right)}{52.8302(s+6)\left(s^{2}+3.2181 s+67.9875\right)}(4.12)
$$

The performance of this controller is discussed in the next section.

\subsection{SIMULATION RESULTS}

The controller $c(s)$ designed in the previous section was simulated with the family of plants described by the parameter changes in Table 3.2. A simulated lane change, shown in Figure 5.1, was the desired trajectory.

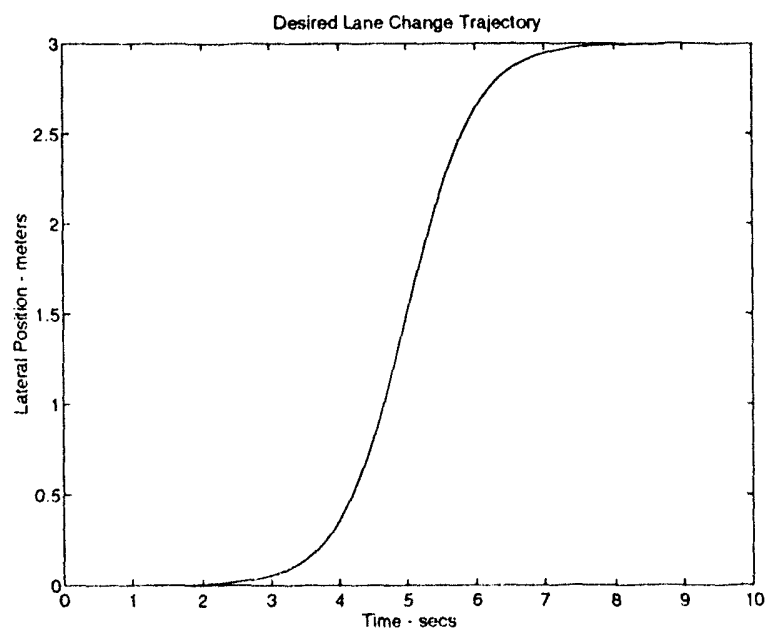

Figure 5.1, Lane Change Trajectory

The closed-loop response of the family of plants is shown in Figure 5.2. Note that all of the closed-loop systems have stable responses, as expected. However, the overshoot of the plants in the family varies from 6 to 20 percent. If this is undesirable, the performance of the control system may be modified by a choice of a different $u(s)$. The poles of $u(s)$ are the poles of the closed-loop system with the nominal plant $p_{0}(s)$ when the uncertainty is chosen as a fraction of the nominal plant. 


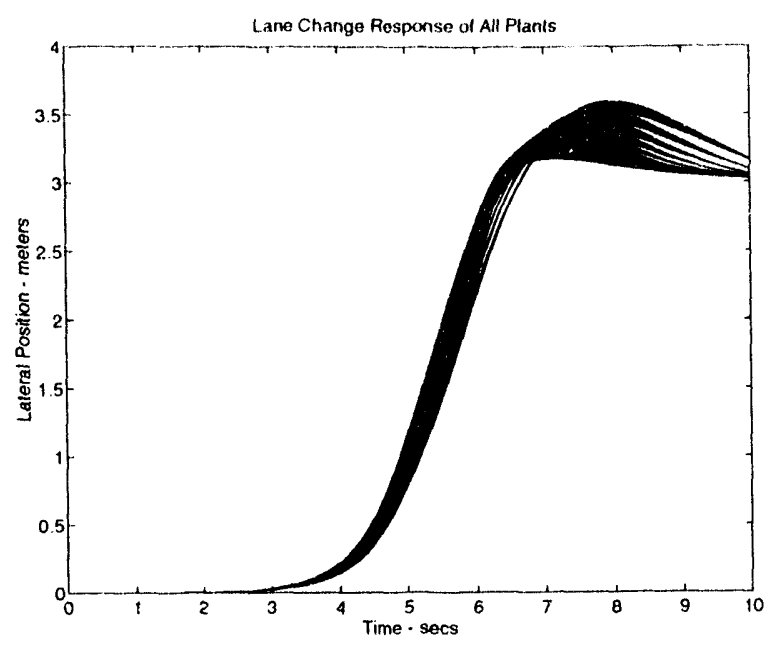

Figure 5.2, Lane Change Response of the Family of Plants

The next section discusses some of the advantages and limitations of this controller design, as well as future plans.

\subsection{SUMMARY \& CONCLUSIONS}

Vehicle lateral dynamics are affected by vehicle mass, longitudinal velocity, vehicle inertia, and the cornering stiffness of the tires. All of these parameters are subject to variation, even over the course of a single trip. This paper describes a robust lateral controller design which models the parameter uncertainty as unstructured perturbations in the frequency domain. A nominal car model was chosen, and then a bound on the frequency domain uncertainty was determined by simulation as the velocity and cornering stiffness were varied. The frequency domain uncertainty bound was presented as the ratio $\left|r(s) / p_{0}(s)\right|$. After determining a suitable uncertainty bound, a controller was designed and the family of closed-loop systems was simulated. The family of systems was stable, but the overshoot varied between 6 and 20 percent for a simulated lane change. If this performance is unacceptable, the performance of the system may be varied by selecting the poles of $u(s)$, which correspond to the poles of the closed-loop system with the nominal plant. For these simulations, the location of the lane sensor was the center of gravity. Moving the sensor to the front of the vehicle improves the system damping also.

One advantage of the robust control approach presented in this paper is that a single fixed controller can guarantee stability, and some performance, for a system with the prescribed uncertainty. This eliminates the need for gain scheduling, or some form of adaptive control. Because the uncertainty model is unstructured, other errors in system modeling, as well as disturbances, can still result in a system which is in the class $C\left(p_{0}(s), r(s)\right)$, and therefore closed-loop stable.

Difficulties with the approach presented in this paper include determining the nominal plant, $p_{0}(s)$, as well as the uncertainty bound. The approach taken was to choose a nominal plant, and then determine a frequency bound for the different parameter changes. This limits the magnitude of the parameter changes that will provide an SBR solution for $u(s)$ (the ratio $\left|r(s) / p_{0}(s)\right|$ can be greater than 1 if the parameter changes are too large). An alternate approach would be to determine the expected parameter changes, and then find the envelope of the family of transfer functions. The nominal plant could then be chosen based on the shape of the envelope.

Another difficulty with the approach presented in this paper is the limited performance guarantees that can be expected. At best, the poles of the family of closedloop systems can be placed to the left of a certain point on the real axis, providing a degree-of-stability guarantee [28]. It would be desirable to place all of the poles of the family of closed-loop systems in a certain region (D-stability). This is an area of future research. However, there is a tradeoff between the magnitude of the uncertainty bound and the degree-ofstability available.

Future plans include full-scale testing of the controller on a 1 mile test track located at Sandia National Laboratories. A buried wire reference system is currently being used to determine vehicle position relative to the lane. Field testing should provide valuable results on the validity of the controller design approach, as well as a better vehicle model. One application of a low-level lateral control system is automatic vehicle operation in an automated highway system (AHS). However, other exciting applications include automatic lane holding and collision avoidance to improve safety.

\subsection{REFERENCES}

I. V. K. Zworykin and L. E. Flory, "Electronic Control of Motor Vehicles on the Highway," in Highway Res. Rec., Proc. of 37th Annual Meeting of the Highway Research Board, 1958. 
2. K. Cardels, "Automatic Car Controls for Electronic Highways", General Motors Research Lab, General Motors Corp.. Warren, MI, Report GMR-276, June 1960).

3. R. E. Fenton and R. J. Mayhan, "Automated Highway Studies at the Ohio State University - An Overview", IEEE Transactions on Vehicular Technology, Vol. 40., No. 1, February 1991.

4. W. H. Cormier and R. E. Fenton, "On the Steering of Automated Vehicles - A Velocity-Adaptive Controller," IEEE Trans. Veh. Technol., vol. VT29, November 1980.

5. R. E. Fenton, et al, "Advances Toward the Automated Highway," in Highway Res. Rec., Proceedings of the 50th Annual Meeting of the Highway Research Board, 1971.

6. J. G. Bender and R. E. Fenton, "On the Flow Capacity of Automated Highways," Transportation Science, Vol. 1, Feb. 1970, pp. 5263.

7. K.W. Olson, et al, "A System for Automatic Vehicle Lateral Guidance," in Highway Res. Rec., Proccedings of the 48th Annual Meeting of the Highway Research Board, 1969.

8. A. S. Hauksdottir and R.E. Fenton, "State Observers and State-Feedback Controllers for a Class of Nonlinear Systems," Int. J. Contr., vol.

9. R. E. Fenton, et al, "On the Steering of Automated Vehicles: Theory and Experiment," IEEE Trans. Automat. Contr., vol. AC-21, June 1976, pp. 306-315.

10. K. W. Olson, "Wire-reference Configurations in Vehicle Lateral Control," iEEE Trans. Veh. Technol., vol. VT-26, pp. 161-172, May 1977.

11. R. E. Fenton and S. S. Murphy, " A Microprocessor-based, Vehicle Lateral Controller," in Proc. 31st IEEE Veh. Technol. Soc. Conf., Washington, DC, April 6-8, 1981.

12 R. J. Mayhan and R. A. Bishel, "A Two-Frequency Radar for Vehicle Automatic Lateral Control," IEEE Trans. Veh. Technol., vol. VT-31, no. 1, Feb. 1982.

13. S. E. Shladover, "Advanced Vehicle Control Systems (AVCS)," Proc. of the 1990 Intl. Congress on Transportation Electronics, SAE paper no. 901129.

14. K. S. Chang, et al, "Experimentation with a Vehicle Platoon System," Proc. of the 1991 Vehicle Navigation \& Information Systems Conference, Dearborn, MI, Oct. 20-23, 1991.

15. S. E. Shladover, et al, "Automatic Vehicle Control Developments in the PATH Program," IEEE Trans. Veh. Technol., vol. 40, no. 1, Feb. 1991.
16. H. Peng, et al, "A Theoretical and Experimental Study on Vehicle Lateral Control," Proc. of the $A C C, 1992$.

17. J. Ackermann, "Velocity-Independent Yaw Eigenvalues of Four-Wheel Steering Automobiles," Robustness of Dynamic Systems with Parameter Uncertainties, Edited by $M$. Mansour, S. Balemi, and W. Truol, Birkhauser Verlag, Basel 1992, pp. 291-302.

18. J. Ackermann and W. Sienel, "Robust Control for Automatic Steering,", Proc: of the ACC, San Diego, 1992.

19. S. Sheikholeslam and C. A. Desoer, "Combined Longitudinal and Lateral Control of a Platoon of Vehicles," Proc of the ACC, 1992.

20. K. Hayafune and H. Yoshida, "Control Method of Autonomous Vehicle Considering Compatibility of Riding Comfort and Vehicle Controllability," Proc. of the SAE Conf. Automated

Highway/Intelligent Vehicle Systems: Technology and Socioeconomic Aspects, 1990, SAE paper no. 901486.

21. D. A. Pomerleau, "Progress in Neural Networkbased Vision for Autonomous Robot Driving," Proc. of the Intelligent Vehicles '92 Symposium, Detroit, June 1992.

22. M. Caudill, "Driving Solo," AI Expert, September 1991.

23. M. Juberts and D. Raviv, "Vision-Based Vehicle Control for AVCS," Proc. of the Intelligent Vehicles '93 Symposium, Tokyo, July 14-16, 1993, pp. 195-198.

24. H. Kimura, "Robust Stabilizability for a Class of Transfer Functions," IEEE Trans. Automat. Contr., vol. AC-29, no. 9, pp. 788-793, Sept. 1984.

25. G. Zames and A. Francis, "Feedback, Minmax Sensitivity and Optimal Robustness," IEEE Trans. Automat. Contr., vol. AC-28, pp. 585-601, May 1983.

26. P. Dorato, L. Fortuna, and G. Muscato, "Robust Control for Unstructured Perturbations - An Introduction," Springer Verlag, New York, 1992

27. J. Y. Wong, "Theory of Ground Vehicles," John Wiley \& Sons, New York, 1993 (second edition).

28. H. Kimura, et al, "Robust Stability - Degree Assignment and its Application to the Control of Flexible Structures," Int. Journ. of Robust and Nonliner Contr., Vol. 1, 1991, pp. 153-169. 

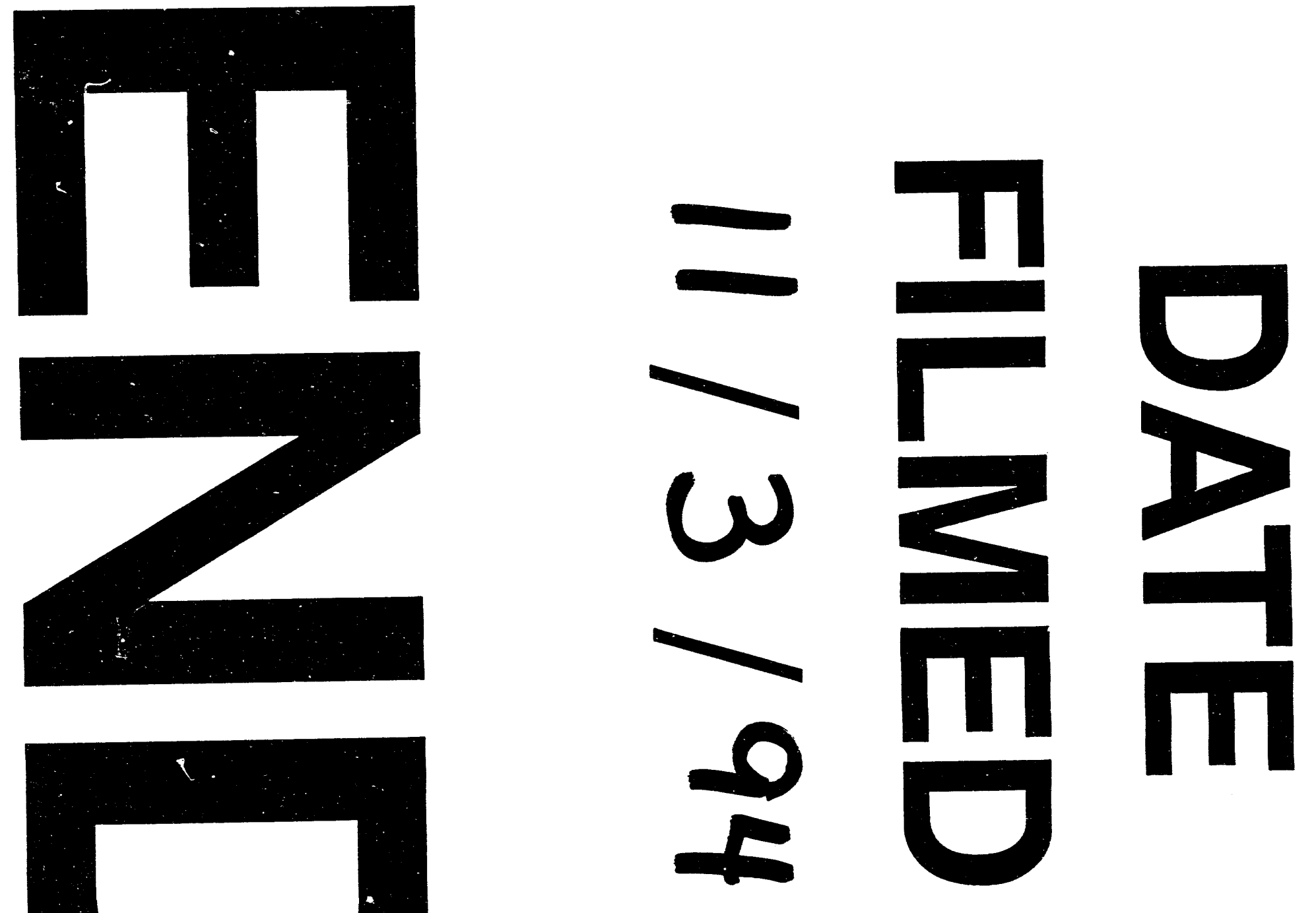
$-1$ 